\title{
ARTICLE
}

\section{Why is it so difficult to measure glucagon-like peptide-1 in a mouse?}

\author{
Johanne A. Windeløv ${ }^{1,2}$ • Nicolai J. Wewer Albrechtsen 1,2,3,4 Rune E. Kuhre ${ }^{1,2}$. \\ Sara L. Jepsen ${ }^{1,2}$ • Daniel Hornburg ${ }^{4}$ Jens Pedersen ${ }^{1,2}$ • Elisa P. Jensen ${ }^{1,2}$. \\ Katrine D. Galsgaard $^{1,2}$ - Marie Winther-Sørensen ${ }^{1,2}$ - Anne Orgaard $^{1,2}$. \\ Carolyn F. Deacon ${ }^{1,2}$ - Matthias Mann ${ }^{3,4}$ - Hannelouise Kissow ${ }^{1}$. \\ Bolette Hartmann $^{1,2}$ • Jens J. Holst ${ }^{1,2}$
}

Received: 26 April 2017 / Accepted: 19 May 2017 /Published online: 1 July 2017

(C) Springer-Verlag GmbH Germany 2017

\begin{abstract}
Aims/hypothesis In humans, glucagon-like peptide-1 (GLP-1) is rapidly degraded by dipeptidyl peptidase- 4 to a relatively stable metabolite, GLP-1(9-36) $\mathrm{NH}_{2}$, which allows measurement of GLP-1 secretion. However, little is known about the kinetics of the GLP-1 metabolite in mice. We hypothesised that the GLP-1 metabolite is rapidly degraded in this species by neutral endopeptidase(s) (NEP[s]).

Methods We administered glucose, mixed meal or water orally to 256 mice, and took blood samples before and 2, 6, 10, 20, 30,60 or $90 \mathrm{~min}$ after stimulation. To study the metabolism of the GLP-1 metabolite, i.v. GLP-1(9-36) $\mathrm{NH}_{2}(800 \mathrm{fmol})$ or saline $(154 \mathrm{mmol} / 1 \mathrm{NaCl})$ was administered to 160 mice, some of which had a prior injection of a selective NEP $24.11 \pm$ inhibitor
\end{abstract}

Johanne A. Windeløv and Nicolai J. Wewer Albrechtsen contributed equally to this study.

Electronic supplementary material The online version of this article (doi:10.1007/s00125-017-4347-7) contains peer-reviewed but unedited supplementary material, which is available to authorised users.

Jens J. Holst

jjholst@sund.ku.dk

1 Department of Biomedical Sciences, Faculty of Health and Medical Sciences, University of Copenhagen, Blegdamsvej 3B, 2200 Copenhagen, Denmark

2 NNF Center for Basic Metabolic Research, Faculty of Health and Medical Sciences, University of Copenhagen,

Copenhagen, Denmark

3 Novo Nordisk Foundation Center for Protein Research, University of Copenhagen, Copenhagen, Denmark

4 Department of Proteomics and Signal Transduction, Max Planck Institute of Biochemistry, Martinsried, Germany (candoxatril, $5 \mathrm{mg} / \mathrm{kg}$ ) or saline. Blood was collected before and 1, 2, 4 and $12 \mathrm{~min}$ after GLP-1/saline injection. Plasma GLP-1 levels were analysed using a customised single-site C-terminal ELISA, two different two-site ELISAs and MS. Results GLP-1 secretion profiles after oral glucose administration differed markedly when assayed by C-terminal ELISA compared with sandwich ELISAs, with the former showing a far higher peak value and AUC. In mice injected with GLP1(9-36) $\mathrm{NH}_{2}$, immunoreactive GLP-1 plasma levels peaked at approximately $75 \mathrm{pmol} / \mathrm{l}$ at $1 \mathrm{~min}$ when measured with sandwich ELISAs, returning to baseline ( $\sim 20 \mathrm{pmol} / \mathrm{l})$ after $12 \mathrm{~min}$, but remained elevated using the $\mathrm{C}$-terminal ELISA ( $\sim 0 \mathrm{pmol} / \mathrm{l}$ at $12 \mathrm{~min}$ ). NEP 24.11 inhibition by candoxatril significantly attenuated GLP-1(9-36) $\mathrm{NH}_{2}$ degradation in vivo and in vitro. MS identified GLP-1 fragments consistent with NEP 24.11 degradation.

Conclusions/interpretation In mice, the GLP-1 metabolite is eliminated within a few minutes owing to endoproteolytic cleavage by NEP 24.11. Therefore, accurate measurement of GLP-1 secretion in mice requires assays for NEP 24.11 metabolites. Conventional sandwich ELISAs are inadequate because of endoproteolytic cleavage of the dipeptidyl peptidase4-generated metabolite.

Keywords ELISA · GLP-1(9-36) $\mathrm{NH}_{2}$ • Gut hormone · In vivo $\cdot$ Mice
Abbreviations
DPP-4 Dipeptidyl peptidase-4
GIP Glucose dependent insulinotropic peptide
GLP-1 Glucagon-like peptide-1
NEP Neutral endopeptidase 


\section{Introduction}

The incretin hormone glucagon-like peptide-1 (GLP-1) is secreted from enteroendocrine $\mathrm{L}$ cells of the gastrointestinal mucosa [1] in response to several nutrients $[2,3]$. When intact GLP-1(7-36) $\mathrm{NH}_{2}$ (also termed active GLP-1) enters the capillaries of the small intestine, it is rapidly degraded $\mathrm{N}$-terminally by the enzyme dipeptidyl peptidase-4 (DPP-4) to form the metabolite GLP-1(9-36) $\mathrm{NH}_{2}$, which is devoid of insulinotropic activity [4-6]. Consequently, only a minor fraction $(\sim 8 \%)$ of secreted GLP-1 reaches the target organs in its intact form [7]. Inhibition of DPP-4 causes levels of circulating intact GLP$1(7-36) \mathrm{NH}_{2}$ to increase several fold; therefore, DPP-4 inhibitors are used as glucose-lowering agents in individuals with type 2 diabetes [8]. Because of the rapid degradation, circulating levels of the intact hormone are often below the detection limit of assays. Assays reacting with the amidated C-terminal, however, will measure both the intact hormone and the metabolite ('total GLP-1') and are therefore used to estimate secretion of GLP-1 in humans (Fig. 1) [9]. However, GLP-1 degradation may also involve endoproteolytic mechanism(s) (e.g. catalysis by neutral endopeptidase [NEP] 24.11) [10-12]. In mice, measurements of total GLP-1 secretion have given inconsistent results, with most stimuli resulting in insignificant changes [13-19]. The stability of the primary GLP-1 metabolite, (936) $\mathrm{NH}_{2}$, which forms the basis for the common 'total GLP-1 assays', is unknown in mice, primarily owing to a lack of adequate immuno-based quantification technologies (assays). As a result, relatively little is known about GLP-1 secretion in mice.

We investigated the secretory profile of GLP-1 and its primary metabolite in mice using an array of biochemical techniques, including a novel customised bead-based fluorescent assay and a highly sensitive MS-based platform [20].

\section{Methods}

\section{Animal studies}

Mice All animal experiments were approved by the Danish National Committee for Animal Studies, Ministry of Justice (2013-15-2934-00833), and were performed in accordance with EU Directive 2010/63/EU, Danish legislation governing animal experimentation (1987) and guidelines from the National Institutes of Health (publication number 85-23). Female and male C57BL/6JRj mice, aged 10-12 weeks, were obtained from Janvier Labs (Saint-Berthevin, France). Mice were housed in groups of six to eight in individually ventilated cages, with a $12 \mathrm{~h}$ light cycle (lights on 06:00-18:00) and ad libitum access to standard chow (Altromin Spezialfutter, Lage, Germany) and water. To minimise stress on the day of the experiment, the mice were weighed and tail-marked the day before.
Orally stimulated GLP-1 secretion in conscious mice Female mice $(n=256)$ were fasted for 6 h $(8: 00-14: 00)$ with free access to water. At time 0 , the animals were orally gavaged with $0.004 \mathrm{ml} / \mathrm{g}$ body weight of: (1) D-glucose, $2 \mathrm{~g} / \mathrm{kg}$ body weight, $50 \% \mathrm{wt} / \mathrm{vol}$. (Sigma-Aldrich, St Louis, MO, USA); (2) mixed meal NAN2 Pro mixture (Nestlé, Vevey, France); or (3) tap water. A maximal single blood sample $(\sim 400 \mu \mathrm{l})$ was obtained via a facial vein at $0,2,6$, $10,20,30,60$ or $90 \mathrm{~min}$ after oral gavage $(n=6-10$ per time point per group), after which the animals were euthanised. Animals designated for sampling at time $0 \mathrm{~min}$ did not receive any oral gavage. Blood glucose was measured directly after collection using a handheld glucometer (Accu-Chek Compact Plus; F. Hoffmann-La Roche, Basel, Switzerland). Blood was transferred into pre-chilled EDTA-coated tubes (Microvette 500 K3E; Sarstedt, Nümbrecht, Germany) and centrifuged $\left(1650 \mathrm{~g}, 4^{\circ} \mathrm{C}, 15 \mathrm{~min}\right)$. Plasma was transferred to Eppendorf tubes and immediately frozen on dry ice according to optimised sample handling procedures [21]. Data for mixed meal are shown in electronic supplementary material (ESM) Fig. 1.

Gastrointestinal biopsies Female mice $(n=6)$ were anaesthetised by i.p. injection with a mixture of ketamine $(90 \mathrm{mg} / \mathrm{kg}$; Ketaminol Vet.; MSD Animal Health, Madison, NJ, USA) and xylazine (10 mg/kg; Rompun Vet.; Bayer Animal Health, Leverkusen, Germany). The small intestine and stomach were harvested and thoroughly rinsed in cold PBS, and $1 \mathrm{~cm}$ samples were snap frozen on dry ice and stored at $-80^{\circ} \mathrm{C}$ until protein extraction, as described previously [22]. Extracts were purified using pH-resistant $\mathrm{tC} 18$ cartridges (Waters, Hedehusene, Denmark), dried under a gentle stream of compressed air overnight and reconstituted in $1 \mathrm{ml}$ of TRIS buffer (100 mmol/1 TRIS buffer [Sigma-Aldrich] supplemented with $0.1 \%$ [wt/vol.] human serum albumin [Merck, Darmstadt, Germany], $20 \mathrm{mmol} / \mathrm{l}$ EDTA and $0.6 \mathrm{mmol} / \mathrm{l}$ thimerosal [Sigma Chemical Co., St Louis, MO, USA]; pH 8.5), and further diluted in assay buffer to ensure that the measured concentrations were within the sensitive ranges of the respective assays.

Perfused upper small intestine Male mice $(n=6)$ were anaesthetised as described above, and the upper small intestine was isolated and perfused as previously described [23].

Injection of GLP-1(9-36) $\mathbf{N H}_{\mathbf{2}}$ Female mice $(n=160)$ were anaesthetised with isoflurane (Baxter, Lillerod, Denmark; flow concentration: $1.5 \%$ [vol./vol.]). Candoxatril (a selective NEP 24.11 inhibitor $[24,25] ; 5 \mathrm{mg} / \mathrm{kg}$, dissolved in $0.9 \% \mathrm{NaCl}$, provided by J. Lundbeck, Novo Nordisk, Måløv, Denmark) or saline $(154 \mathrm{mmol} / \mathrm{l} \mathrm{NaCl})$ was administered as an i.v. bolus injection into the vena cava through an insulin needle $2 \mathrm{~min}$ before injection of GLP-1. At time 0 , either 800 fmol GLP-1(9- 
a
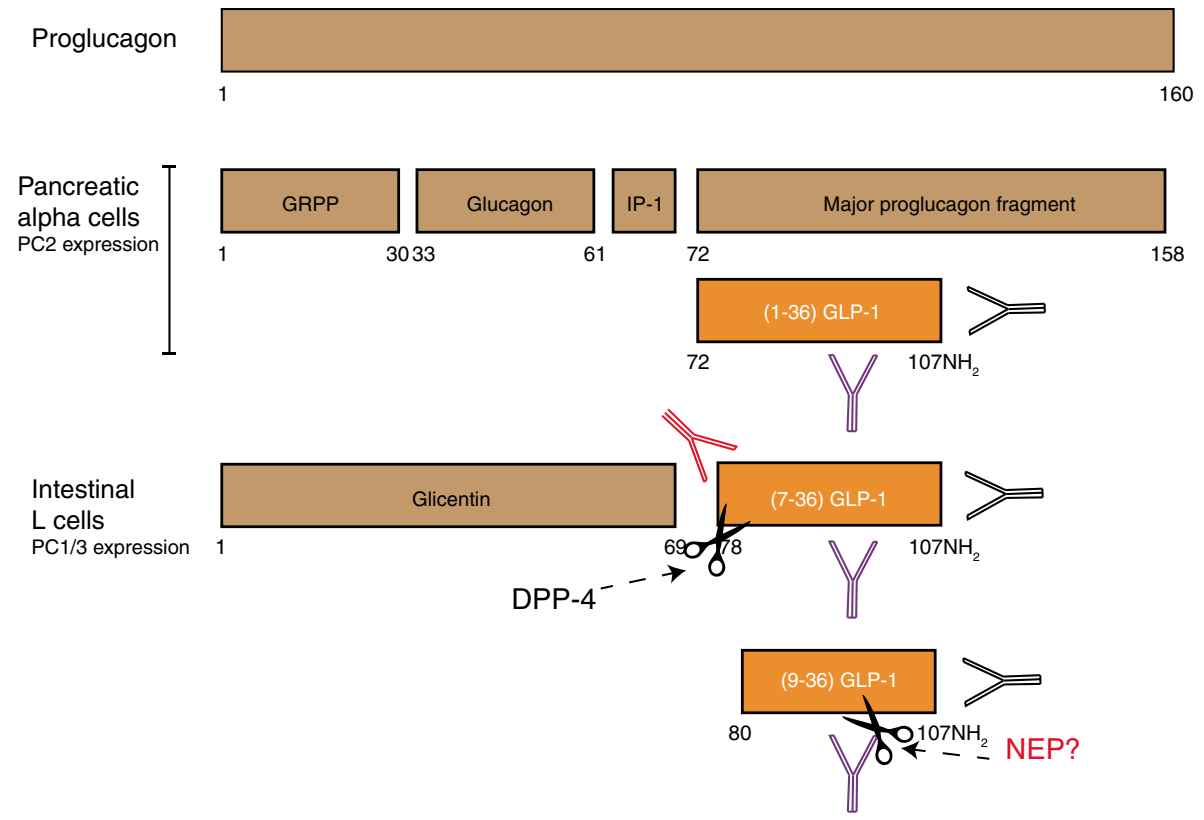

b

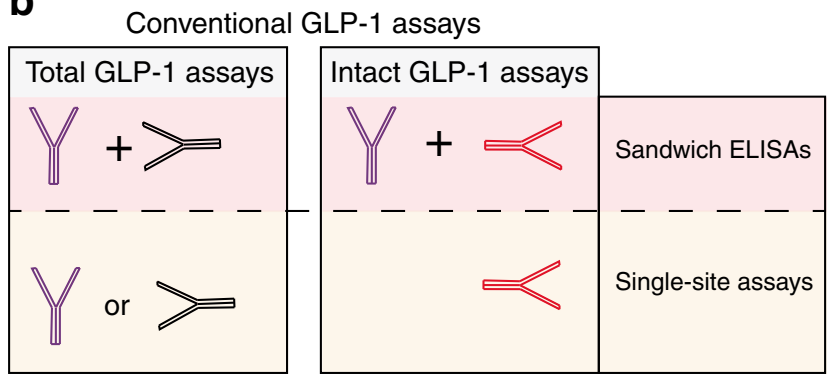

C

Sandwich ELISAs

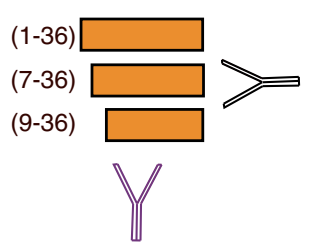

C-terminal ELISA

$(1-36) \square$

$(7-36)$

$(9-36)$

$(\mathrm{X}-36)$

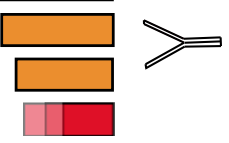

Fig. 1 Processing of proglucagon and conventional GLP-1 assays. (a) Overview of the processing of proglucagon to GLP-1(1-36) $\mathrm{NH}_{2}$ in pancreatic alpha cells (mediated by prohormone convertase 2 ) and to intact GLP-1 [(7-36) $\left.\mathrm{NH}_{2}\right]$ (mediated by prohormone convertase 1/3) in intestinal $\mathrm{L}$ cells. The primary metabolite, GLP-1(9-36) $\mathrm{NH}_{2}$, is formed from GLP1(7-36) $\mathrm{NH}_{2}$ after N-terminal cleavage by DPP-4. (b) Conventional GLP-1 assays include assays measuring 'total' and 'intact' GLP-1, respectively. In addition, each of these two assay types may be further divided into assays using sandwich ELISA technology (two antibodies) or assays using singlesite antibodies. In contrast to the two-site total GLP-1 sandwich ELISAs (depicted as purple + black antibodies), C-terminal assays are not affected by N-terminal or mid-terminal cleavage of the target molecule. Intact GLP1 assays may be based on single-site $\mathrm{N}$-terminal antibodies (depicted as red antibody) or two-site sandwich ELISAs (depicted as purple + red antibodies). (c) Reactivity (specificity) of the applied assays (sandwich ELISAs:

36) $\mathrm{NH}_{2}$ (see below) or saline was administered through the inferior vena cava (injection volume $100 \mu \mathrm{l}$ ). A maximal blood sample $(\sim 400 \mu \mathrm{l})$ was drawn from the inferior vena cava at 0,1 , $2,4,8$ or 12 min after injection ( $n=4-8$ per time point), after which the animals were euthanised. Blood was immediately transferred into pre-chilled EDTA-coated microtest tubes (VWR, Søborg, Denmark). Animals designated for sampling at time $0 \mathrm{~min}$ did not receive any i.v. injection. Blood glucose was measured immediately, as described above. Blood was centrifuged and handled as described above.

EZGLP1T-36K and K150JVC-1; C-terminal ELISA: MMHMAG-84K). The shading on the $\mathrm{X}-36$ bar indicates that the exact length is unknown. The black antibodies shown (b, c) refer to a C-terminal GLP-1 antibody that may be specific for the amidated C-terminus, the glycine-extended Cterminus (denoted 'X-37'; not shown) or both. The red antibodies shown refer to N-terminal GLP-1 antibodies that do not bind to N-terminally elongated GLP-1 [e.g. (1-36) $\mathrm{NH}_{2},(1-37) \mathrm{NH}_{2}$ ] or N-terminally truncated GLP-1 [e.g. (8-36) $\mathrm{NH}_{2},(9-36) \mathrm{NH}_{2}$ ]. The purple antibodies refer to a sideviewing antibody that, in principle, binds equally to all isoforms of GLP-1, including (1-36) $\mathrm{NH}_{2},(7-36) \mathrm{NH}_{2}$ and $(9-36) \mathrm{NH}_{2}$. Such an antibody is not directed towards the $\mathrm{C}$-terminus or the $\mathrm{N}$-terminus, but somewhere in between. The epitope of these antibodies may vary from assay to assay, but in most cases it is located at sequences towards the N-terminus of the GLP-1 metabolite [(9-36) $\left.\mathrm{NH}_{2}\right]$. GRPP, glicentin-related polypeptide; IP-1, intervening peptide 1 ; $\mathrm{PC}$, prohormone convertase

In vitro degradation of GLP-1(9-36) $\mathbf{N H}_{2}$ Heparinised mouse plasma was obtained from Equitech-Bio (Kerrville, TX, USA). In addition, EDTA plasma was obtained as follows: female mice $(n=38)$ were anaesthetised with isoflurane, and blood was drawn from the inferior vena cava, pooled into $6 \mathrm{ml}$ EDTA-coated tubes (VWR) and centrifuged (1650 g, $4^{\circ} \mathrm{C}, 15 \mathrm{~min}$ ). Plasma was separated immediately and kept chilled. Synthetic GLP-1(9-36) $\mathrm{NH}_{2}$ (see below) was added to each plasma pool (final concentration 200 pmol). Each pool was then divided into four equal portions, to which was added 
$10 \mu$ of: (1) saline; (2) DPP-4 inhibitor (valine pyrrolidide, a gift from Novo Nordisk, Denmark; final concentration $0.01 \mathrm{mmol} / \mathrm{l}$ ); (3) NEP 24.11 inhibitor (phosphoramidon; Sigma-Aldrich, Brøndby, Denmark; final concentration $3.5 \mu \mathrm{mol} / \mathrm{l}$ ); or (4) an inhibitor cocktail (Pefabloc; SigmaAldrich; final concentration $1 \mathrm{mg} / \mathrm{ml}$ ). Four aliquots (each $250 \mu \mathrm{l}$ ) from each portion were removed immediately after the respective additions and transferred to low-adsorption Nunc tubes (VWR). The remaining plasma was kept cold (on ice) until analysis and served as 'time 0', while the aliquoted samples were kept at room temperature $\left(27.1^{\circ} \mathrm{C}\right)$. Samples $(100 \mu \mathrm{l})$ were then taken from each of the aliquots after 1 and $3 \mathrm{~h}$, chilled immediately and kept cold until analysis on the same day. This procedure was repeated with a second set of tubes run in parallel, but using assay buffer (provided in the total GLP-1 sandwich ELISA [EZGLP1T$36 \mathrm{~K}$, see later description]) instead of plasma.

\section{Biochemical analysis}

Peptide Synthetic GLP-1(9-36) $\mathrm{NH}_{2}$ was obtained from Bachem (Bubendorf, Switzerland). Prior to use, its structure and composition was verified by MS and quantitative amino acid analysis (duplicate determination) at the Department of Systems Biology, Enzyme and Protein Chemistry of the Danish Technical University (Kongens Lyngby, Denmark) and dissolved in phosphate buffer containing 1\% (wt/vol.) human serum albumin (Calbiochem [San Diego, CA, USA], an affiliate of Merck) and stored at $-20^{\circ} \mathrm{C}$. Peptide concentrations in aliquots of the stock solution were verified using an in-house RIA employing a 'side-viewing' GLP-1 antiserum [26]. A fragment of GLP-1(9-36) $\mathrm{NH}_{2}$, FIAWLVKGR-NH [corresponding to GLP-1(28-36) $\mathrm{NH}_{2}$ ] was customsynthesised by CASLO (Lyngby, Denmark).

Assays Plasma levels of 'total GLP-1' [which includes both the (7-36) $\mathrm{NH}_{2}$ and (9-36) $\mathrm{NH}_{2}$ moieties and any N-terminally extended forms, including GLP-1(1-36) $\mathrm{NH}_{2}$ from the pancreas, if present] were quantified before and $15 \mathrm{~min}$ after oral glucose administration using two sandwich (two-site) ELISAs and one single-site C-terminal ELISA. One of the sandwich ELISAs employed a 'side-viewing' antibody as capture and a Cterminal HRP-conjugated antibody for detection (catalogue no. EZGLP1T-36K, Merck-Millipore, Billerica, MA, USA), while the antibody epitopes are not described for the other sandwich ELISA (total GLP-1 sandwich ELISA; Meso Scale Discovery, catalogue no. K150JVC-1, Rockville, MD, USA). For the single-site ELISA, also designed to measure 'total GLP-1', we used a newly developed customised xMAPbased assay (catalogue no. MMHMAG-84K, MerckMillipore), which employed the same C-terminal antibody as used for detection in the Merck-Millipore sandwich ELISA, but without enzyme conjugation. Instead, the antibodies were coupled to fluorescent-coded magnetic beads (MagPlex-C Microspheres; Millipore). After the analyte was bound to the antibody-coupled bead, a biotinylated detection antibody was added, followed by incubation with streptavidin-phycoerythrin conjugate. Subsequently, the beads were subjected to flow cytometry-based detection using a Luminex laser-based analyser (Luminex 200; Luminex, Austin, TX, USA). The median fluorescent intensities from eight calibrators were used to interpolate concentrations in plasma samples using fivevariable logistic regression.

Plasma levels of GLP-1(9-36) $\mathrm{NH}_{2}$ were assessed using a specific two-site sandwich ELISA (prototype, not yet commercially available; code name JP27788) from IBL (Hamburg, Germany). Total GLP-1 in the venous effluent from the perfused small intestine and in tissue biopsies from the gastrointestinal tract was measured using the EZGLP1T-36K (see above) and by a validated in-house C-terminally-directed RIA (code name 89,390 [27]). Plasma samples from oral gavages were also subjected to two-site ELISAs for measurement of insulin (Crystal Chem, Downers Grove, IL, USA), glucagon (Mercodia, Uppsala, Sweden) and glucose-dependent insulinotropic peptide (GIP; catalogue no. EZRMGIP-55K, Merck-Millipore). All provided quality controls were within the expected ranges, and all commercial analyses were performed according to manufacturers' protocols.

MS-based proteomics Pooled plasma $(500 \mu \mathrm{l})$ from the in vivo degradation study [injection of 800 fmol GLP-1(936) $\mathrm{NH}_{2}$ ] was purified and analysed in technical triplicates using a validated platform for the detection of low-abundant peptides, as previously described [20]. We employed the 'unspecific search' option (assuming no enzymatic specificity for peptides between six and 29 amino acids) and searched the purified plasma fraction against the GLP-1 sequence as well as a list of common contaminants provided with MaxQuant (www.coxdocs.org/doku.php?id=maxquant:common: download_and_installation; version 1.5.4.3) [28]. To assess the presence of potential GLP-1 in vivo, cleavage products removed peptides that could have been derived from chymotrypsin (assuming N-terminal cleavage of L, M, F, W and Y). Identified peptides (at least two valid values in technical triplicates) were mapped to GCG, and the confidence of identification is provided via the Andromeda score [29].

\section{Statistics}

The experimenters were blind to outcome assessment but not to group assignment. To assess distribution and homoscedasticity in datasets, we applied the Shapiro-Wilk test (swilk command) and drafted residual plots. AUCs were calculated using the trapezoidal rule, and for net AUC we used 'baseline subtracted data' that included both increments and decrements. One-way ANOVA, corrected by a post hoc analysis 
(Sidak) for multiple testing, was used for testing differences between more than two groups of data. Unpaired two-sided $t$ tests were used to assess differences between two groups. Data are expressed as mean \pm SEM. A $p$ value of $<0.05$ was considered significant. Calculations were made using GraphPad Prism (version 6.04 for Windows; GraphPad Software, La Jolla, CA, USA). The Adobe CS6 software suite (Adobe, San Jose, CA, USA) was used for illustrations.

\section{Results}

\section{Secretory profiles of gastrointestinal and pancreatic hormones during oral administration of glucose or water in conscious mice}

Oral glucose gavage resulted in robust $(p<0.001)$ increases in blood glucose that peaked $10 \mathrm{~min}$ after administration (baseline $8 \pm 1$ vs $24 \pm 1 \mathrm{mmol} / \mathrm{l}$ ) (Fig. 2a). Blood glucose levels were significantly $(p<0.001)$ lower during oral administration of water (peak level $9 \pm 3 \mathrm{mmol} / \mathrm{l}$ ) compared with glucose, but baseline values did not differ.

Oral glucose resulted in a twofold increase in plasma levels of total immunoreactive GLP-1 [(1-/7-/9-36) $\left.\mathrm{NH}_{2}\right](p<0.01)$ (Fig. 2b) compared with baseline, but only at $2 \mathrm{~min}$, when analysed using the sandwich ELISAs. A similar pattern was observed in mice receiving water (Fig. 2b; the data depicted were obtained using the EZGLP1T-36K, but results were similar with K150JVC-1 sandwich ELISA [data not shown]). Using the customised C-terminally directed single-antibody assay (MMHMAG-84K), the secretory profile of GLP-1 (Fig. 2c), with a peak after $10 \mathrm{~min}(60 \mathrm{pg} / \mathrm{ml}, \sim 20 \mathrm{pmol} / \mathrm{l}$; reported in $\mathrm{pg} / \mathrm{ml}$ rather than $\mathrm{pmol} / \mathrm{l}$, as the exact molarity of the peptide picked up by this assay is unknown), was in sharp contrast to the results obtained using the sandwich ELISA (EZGLP1T-36K) for GLP-1 measurement (Fig. 2b). Biopsies from mouse stomachs contained low but detectable concentrations of GLP-1 $(10 \pm 2 \mathrm{pmol} / \mathrm{g}$; well above the lower limit of detection of $\sim 0.1 \mathrm{pmol} / \mathrm{g}$ ) compared with the duodenum $(31 \pm 11 \mathrm{pmol} / \mathrm{g})$ and distal ileum $(74 \pm 21 \mathrm{pmol} / \mathrm{g})$.

Plasma GIP levels also peaked $10 \mathrm{~min}$ after glucose administration. There were no marked GIP changes after the administration of water (Fig. 2d). Plasma glucagon concentrations peaked at $2 \mathrm{~min}$ after stimulation in both groups, followed by a decrease (Fig. 2e). Glucose resulted in robust increases in plasma insulin levels, peaking at $10 \mathrm{~min}$, whereas minimal changes were seen after water (Fig. 2f).

\section{GLP-1 is secreted from the perfused small intestine in mice in response to an intraluminal glucose load}

Luminal glucose $(20 \%)$ stimulation resulted in long-lasting threefold increases in GLP-1 secretion $(p<0.001$; Fig. 3a and ESM Fig. 2) independently ( $p=0.76$ ) of how GLP-1 was measured (C-terminal RIA: 89,390, vs sandwich ELISA: EZGLP1T-36K).

\section{GLP-1(9-36) $\mathrm{NH}_{2}$ is rapidly degraded in vivo}

Injection (i.v.) of GLP-1(9-36) $\mathrm{NH}_{2}$ in mice did not $(p=0.67)$ affect blood glucose compared with injection of isotonic saline (Fig. 3b, ESM Fig. 3a). Immunoreactive GLP-1 concentrations measured with the GLP-1 sandwich ELISA (EZGLP1T-36K) and the (9-36) $\mathrm{NH}_{2}$ specific ELISA increased within the first minute after injection of GLP-1(9-36) $\mathrm{NH}_{2}$, falling quickly thereafter to reach baseline $12 \mathrm{~min}$ after injection (ESM Fig. $3 \mathrm{~b})$. However, when the same samples were analysed using the C-terminally directed single-antibody ELISA, concentrations remained higher than at baseline $(p<0.001)$ for the duration of the experiment. Incremental AUCs mirrored these differences, being approximately threefold higher $(p<0.001)$ for the C-terminal assay compared with the sandwich ELISAs (ESM Fig. 3c). Immunoreactive GLP-1 levels were unchanged in mice receiving saline (ESM Fig. 3c). In mice with prior administration of candoxatril (a selective NEP 24.11 inhibitor, $5 \mathrm{mg} / \mathrm{kg}$ ) immunoreactive GLP-1 concentrations were significantly higher $(p<0.001)$ compared with mice with prior administration of saline (Fig. 3c,d).

\section{In vitro incubations with GLP-1(9-36) $\mathrm{NH}_{2}$}

In control (buffer) experiments, GLP-1(9-36) $\mathrm{NH}_{2}$ was stable over $3 \mathrm{~h}$ (measured with the GLP-1 sandwich ELISA, EZGLP1T-36K) and concentrations were not significantly affected by the inclusion of protease inhibitors (Fig. 3e). In contrast, in mouse plasma (heparin), GLP-1(9-36) $\mathrm{NH}_{2}$ concentrations measured with the same assay were significantly $(p<0.01)$ lower after $1 \mathrm{~h}$ of incubation at room temperature and decreased even further after $3 \mathrm{~h}$ (Fig. 3f). Addition of a DPP-4 inhibitor (valine pyrrolidide) had no effect, whereas both an NEP 24.11 inhibitor (phosphoramidon) and an inhibitor cocktail (Pefabloc, a small molecule non-selective serine protease inhibitor) inhibited GLP-1(9-36) $\mathrm{NH}_{2}$ degradation and stabilised concentrations (Fig. 3f). Similar patterns were observed in pooled mouse plasma collected with EDTA (data not shown).

\section{An MS-based platform identifies fragments consistent with NEP 24.11 cleavage of GLP-1}

Multiple peptide fragments were identified in vivo, whereas none were identified in the parallel buffer experiment (Fig. 4). One fragment (FIAWLVKGR) corresponding to the Cterminus of GLP-1 [GLP-1(28-36) $\mathrm{NH}_{2}$ ] was synthesised and subsequently measured using the C-terminal ELISA (MMHMAG-84K) and the sandwich GLP-1 ELISA 
Fig. 2 GLP-1 and GIP responses differ during an OGTT in mice. (a) Glucose and (b) GLP-1 responses in conscious C57BL/ 6JRJ mice after oral administration of water (triangles) or glucose (circles) estimated using a total GLP-1 sandwich ELISA (EZGLP1T-36K). (c) GLP-1 responses after water or glucose administration, measured using a $\mathrm{C}$-terminal assay (MMHMAG-84K; reported in $\mathrm{pg} / \mathrm{ml}$ rather than $\mathrm{pmol} / \mathrm{l}$, as the exact molarity of the peptide picked up by this assay is unknown). (d) GIP, (e) glucagon and (f) insulin responses. Inserts show the net (n)AUC $\mathrm{An}_{00 \mathrm{~min}}$. The $\mathrm{nAUC}_{0-30 \mathrm{~min}}$ for the first $30 \mathrm{~min}$ were similar (data not shown). Data are presented as means \pm SEM. $* * p<0.01, * * * p<0.001$, unpaired $t$ test; $n=4-12$. Black bars, saline; white bars, glucose

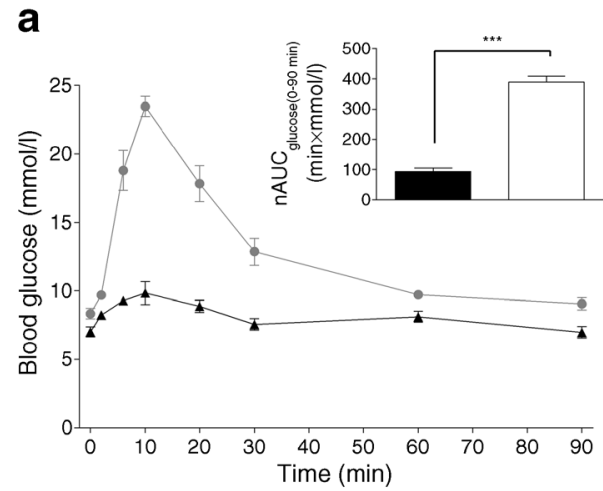

b

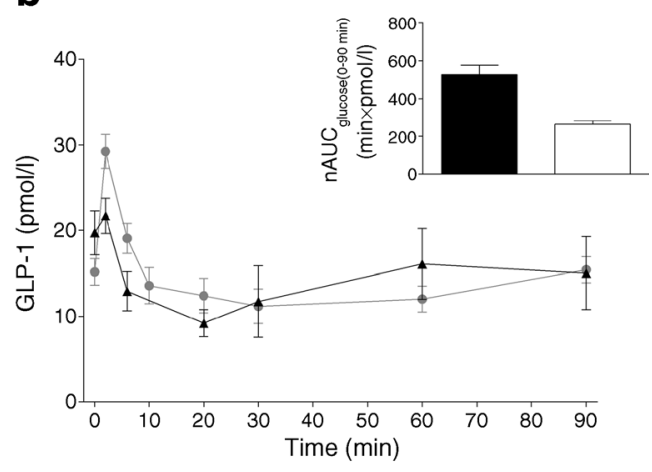

C

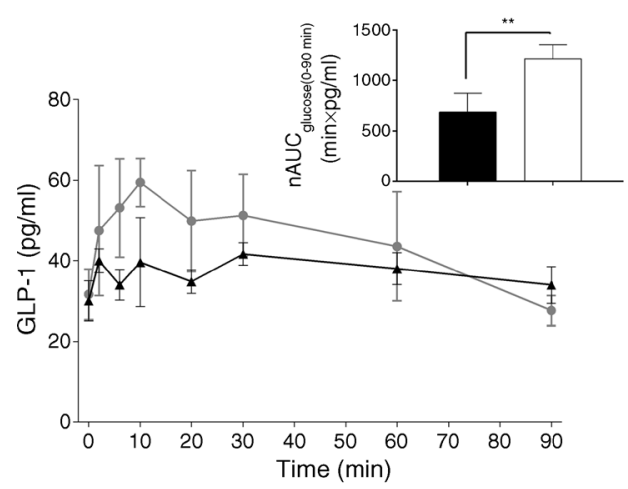

d

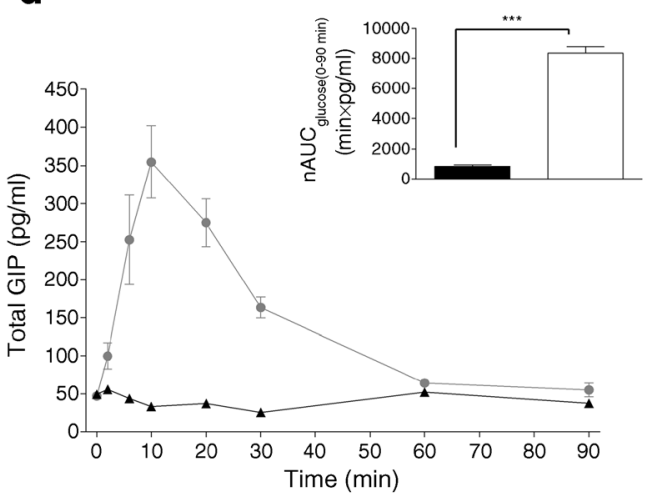

e

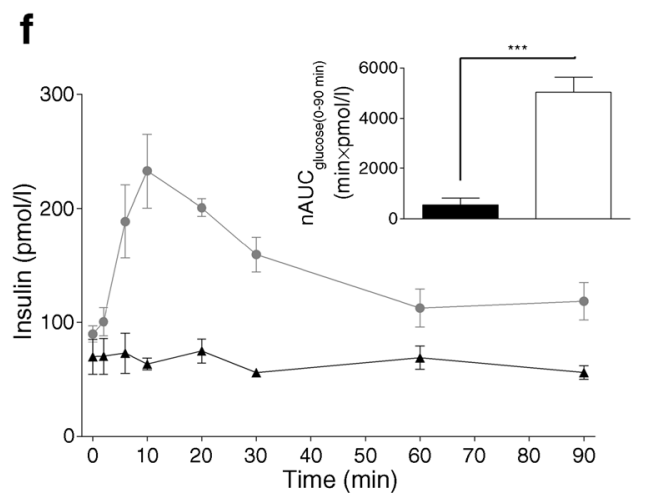

(EZGLP1T-36K) used in the previous experiments. This fragment showed cross-reactivity of $45 \pm 12 \%$ in the C-terminal ELISA, but only $3 \pm 2 \%$ in the sandwich ELISA (both in assay buffer).

\section{Discussion}

Here, we demonstrate that, in addition to degradation by DPP4, GLP-1 in mice undergoes extremely fast endoproteolytic metabolism (probably mediated by NEP 24.11). Accordingly, the dynamics of GLP-1 secretion in vivo in mice can be estimated accurately only by C-terminal assays, whereas sandwich ELISAs provide only weak reflections of the actual secretion (Fig. 1).

Accurate estimation of GLP-1 secretion is a delicate matter and is further complicated by the fact that several commercially available assays are relatively unspecific and/or insensitive [30]. In addition, they often require high sample volumes (100-700 $\mu \mathrm{l}$ ), rendering meaningful estimation of GLP-1 secretion at high time resolution impossible in mice (because of the low blood volume that can be obtained). Previous studies in mice [13-19] have estimated GLP-1 secretion in vivo by measuring 'before vs post stimulation concentrations' (typically at 0 and $15 \mathrm{~min}$ after the administration of a test substance). In one study, intact GLP-1 [(7-36) $\left.\mathrm{NH}_{2}\right]$ (measured using the sandwich ELISA from Linco Research, St Charles, 

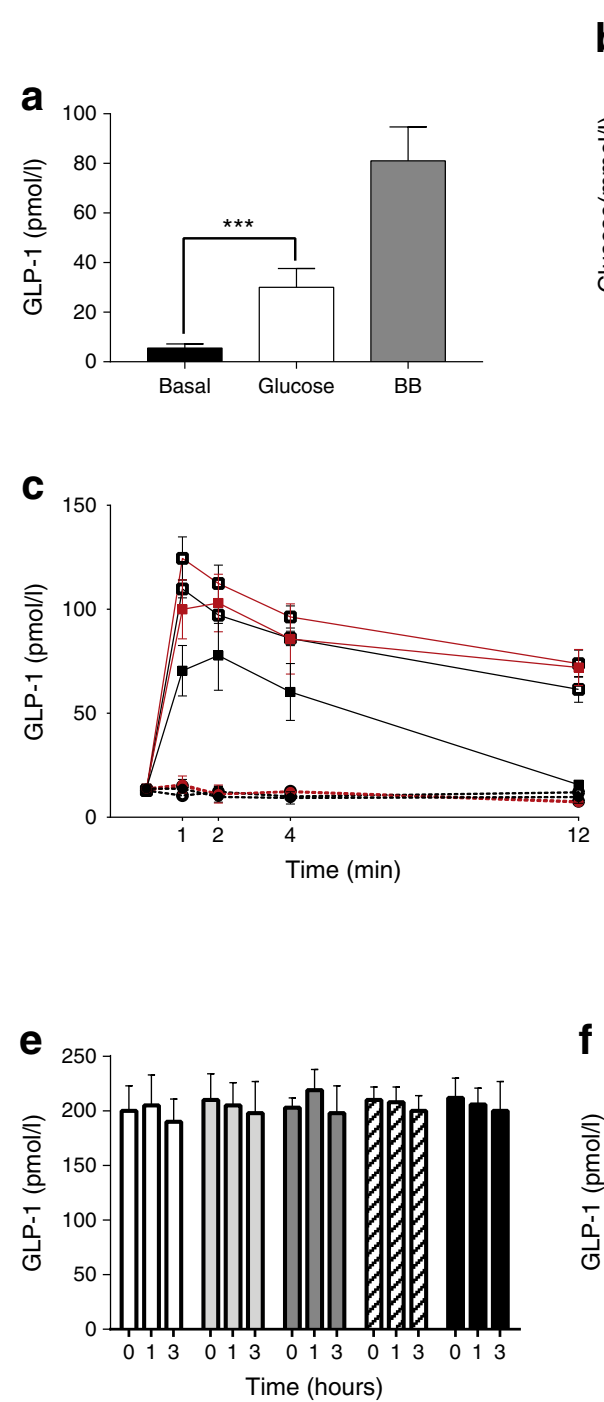

Fig. 3 GLP-1 is secreted from the perfused small intestine in response to glucose, but the major GLP-1 metabolite, $(9-36) \mathrm{NH}_{2}$, is rapidly degraded in vitro and in vivo by NEP 24.11. (a) GLP-1 secretion in response to intraluminal glucose perfusion in the mouse small intestine estimated using the EZGLP1T-36K assay. Bombesin (BB) was used as a positive control. Data represent GLP-1 concentrations at 10-15 min (baseline [basal]) and 18-23 min (20\% luminal glucose) from six perfused small intestine preparations. The effluent concentrations were also measured using a C-terminal in-house RIA (code 390), as shown in ESM Fig. 2. (b) Blood glucose in response to an i.v. administration of $800 \mathrm{fmol}$ GLP1(9-36) $\mathrm{NH}_{2}$ (square, solid line) and saline (circle, dashed line) after prior administration of candoxatril (red) or saline (black) $(n=4-8)$. (c) Immunoreactive GLP-1 in plasma from mice injected with $800 \mathrm{fmol}$ GLP-1(9-36) $\mathrm{NH}_{2}$ (squares) or saline (circles) after prior administration

MO, USA) concentrations of approximately $30 \mathrm{pmol} / 1$ peaked around 15 min after oral stimulation [31], strongly contrasting to the levels obtained by others [32-35] using sandwich ELISA techniques (which usually measure concentrations around $0 \mathrm{pmol} / \mathrm{l}$ ), raising doubts as to the validity of this measurement. Others have used sandwich ELISAs (similar to those described here) and have also reported a rapid increase in immunoreactive GLP-1 within the first few minutes [36,
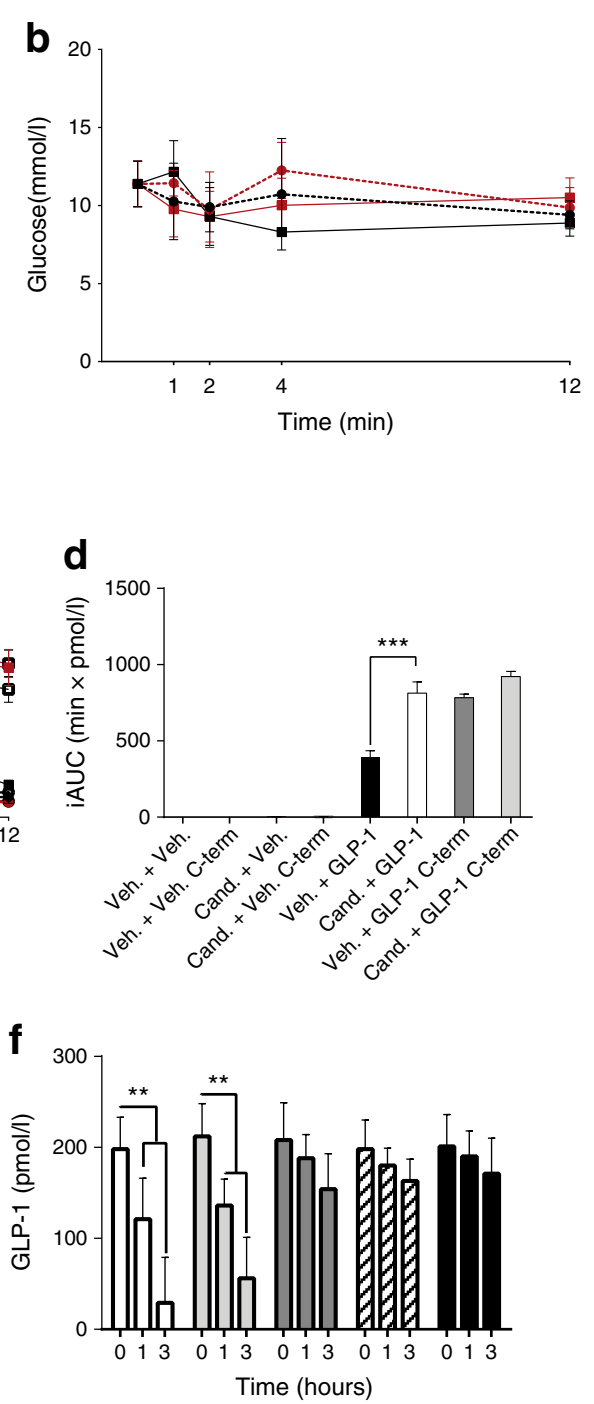

of candoxatril (red) or saline (black), measured by sandwich ELISA (filled symbols, EZGLP1T-36K) and a single-site C-terminal ELISA (open symbols, MMHMAG-84K) $(n=4-8)$. (d) Corresponding incremental iAUC from (c), measured by the sandwich ELISA (EZGLP1T36K) or single-site C-terminal ELISA (MMHMAG-84K); Veh., vehicle; Cand., candoxatril. (e, f) GLP-1 concentrations in buffer (e) and pooled mouse plasma (heparin) (f), spiked with GLP-1(9-36) $\mathrm{NH}_{2}$ and subsequently treated with PBS (white); DPP-4 inhibitor (light grey); NEP 24.11 inhibitor: $3.5 \mu \mathrm{mol} / 1$ phosphoramidon (dark grey) and $7.0 \mu \mathrm{mol} / 1$ phosphoramidon (diagonal stripes); or an inhibitor cocktail (Pefabloc: 4benzenesulfonyl fluoride hydrochloride; black); all samples $(n=4)$ were analysed in duplicate using the sandwich ELISA (EZGLP1T-36K). $* * p<0.01$, ***p $p<0.001$, one-way ANOVA correcting for multiple comparison with the Holm-Šidák algorithm

37] — similar to the glucagon profile described here. Such rapid increases may be due to cross-reactivity in the sandwich assays [30] with the (inactive) pancreatic isoform GLP-1(136) $\mathrm{NH}_{2}$, which is co-secreted with glucagon (probably in response to acute stress elicited by the gavage procedure). However, as demonstrated here, GLP-1 is also produced in the gastric mucosa of mice, although at much lower levels than in the small intestine, but nevertheless raising the 

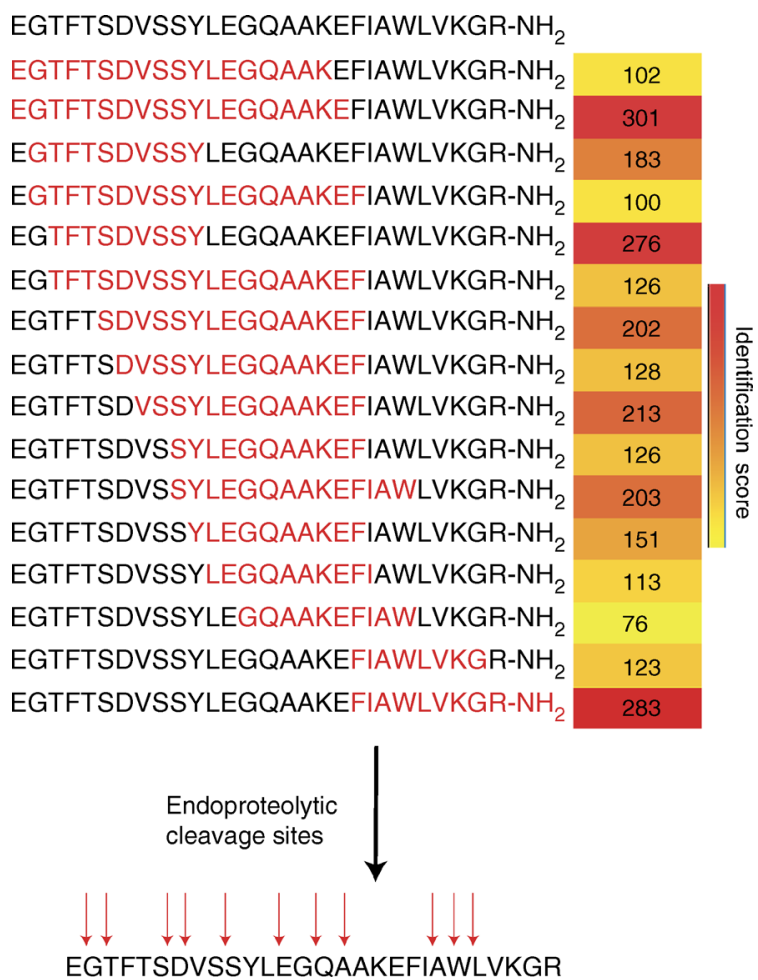

Fig. 4 A high-resolution MS-based platform identifies potential NEP 24.11 cleavage products. 800 fmol GLP-1(9-36) $\mathrm{NH}_{2}$ was injected i.v. into mice $(n=10)$ and, after $12 \mathrm{~min}$, a single $400 \mu \mathrm{l}$ blood sample was obtained from the vena cava inferior. Pooled plasma was subjected to MS-based proteomics. Colours ranging from yellow to red denote increasing Andromeda identification scores (denoted for each of the 16 peptides). The sequence and corresponding cleavage points (arrows) are shown for GLP-1(9-36) $\mathrm{NH}_{2}$. Black represents native GLP-1(9-36) $\mathrm{NH}_{2}$, whereas red represents identified peptide fragments

possibility that the rapid (1-2 min) GLP-1 response could derive from the stomach rather than, or in addition to, pancreatic GLP-1(1-36) $\mathrm{NH}_{2}$ secretion. The development of a specific and sensitive low-volume assay for GLP-1(1-36) $\mathrm{NH}_{2}$ will be required to clarify this possibility, but the similar profiles of glucagon, measured using a validated assay for pancreatic (as opposed to gut) glucagon, support the hypothesis that the early immunoreactive GLP-1 peak may be due to GLP-1(1-36) $\mathrm{NH}_{2}$ from the pancreas.

Given that glucose is a GLP-1 secretagogue, the observation that the early immunoreactive GLP-1 peak actually preceded the peak in blood glucose levels made us question the suitability of the sandwich ELISAs for measuring GLP-1 in mice. Previously validated sandwich total GLP-1 ELISAs [30] have been shown to be reliable for measuring total GLP-1 in humans, presumably because GLP-1(9-36) $\mathrm{NH}_{2}$ is degraded relatively slowly in humans [6], and this also seems to be the case in rats [38]. We therefore hypothesised that, in mice, GLP-1(9-36) $\mathrm{NH}_{2}$ might undergo further rapid endoproteolytic cleavage, thereby precluding assessment of GLP-1 secretion in vivo by methods based on the measurement of full-length GLP-1(9-36) $\mathrm{NH}_{2}$ (e.g. sandwich
ELISAs). Although it has been established that NEPs can degrade GLP-1(7-36) $\mathrm{NH}_{2}$ and $(9-36) \mathrm{NH}_{2}$ in vitro [11, 39, 40], we can now show that this occurs (in vivo) in mice with extreme rapidity and independent of DPP-4, consistent with the recent finding that NEP 24.11 knockout mice have higher plasma levels of GLP-1 [41] and that NEP 24.11 is ubiquitously expressed in endothelial cells [42]. Using a library of immunoassays and a sensitive MS-based platform [20], we have identified fragment(s) identical to the anticipated sequences that would be produced by endoproteolytic cleavage of GLP-1(9-36) $\mathrm{NH}_{2}$ by the NEP 24.11 enzyme [11], including 'DVSSYLEGQAAKE' [GLP-1(15-27) $\mathrm{NH}_{2}$ ] and 'FIAWLVKGR-NH ${ }_{2}$ ' [GLP-1(28-36) $\left.\mathrm{NH}_{2}\right]$, consistent with cleavage of GLP-1 in the mid region of the peptide (EGTFTSDVSSYLEGQAAKE-FIAWLVKGR); in support of this, inhibition of NEP 24.11 (by phosphoramidon and candoxatril) significantly attenuated degradation of GLP$1(9-36) \mathrm{NH}_{2}$ in mouse plasma (when measured by a two-site sandwich ELISA). Notably, GLP-1(9-36) $\mathrm{NH}_{2}$ was stable when incubated in assay buffer, suggesting that the observed degradation in plasma was dependent on proteases present in plasma, rather than representing non-specific instability or analytical inadequacies. Theoretically, the C-terminal fragment, GLP-1(28-36) amide, should be measurable by C-terminal analysis but not with the sandwich ELISAs; this was demonstrated to be the case, using a synthetic replica of the fragment. Accordingly, the new customised C-terminal ELISA revealed preserved GLP-1 immunoreactivity in the in vitro experiments and secretory profiles of GLP-1 in vivo, which, unlike those obtained with the sandwich ELISAs, correlated to those of glucose absorption (blood glucose), GIP and insulin in a physiologically meaningful manner.

It has been suggested that GLP-1(9-36) $\mathrm{NH}_{2}$ may have effects on glucose homeostasis [43] and on the cardiovascular system [44-46]. In rodents, fragments of the GLP-1 metabolite may also have glucoregulatory effects, possibly mediated through hepatocytes [39], in line with previous observations of degradation of the GLP-1 metabolite [10, 40]. In humans, using the same specific sandwich ELISA as applied in this study, GLP-1(9-36) $\mathrm{NH}_{2}$ does not seem to be subject to the same rapid degradation, since the GLP-1 secretory profiles obtained with this assay (in response to oral glucose administration) are comparable with those obtained using a single-site C-terminal specific RIA [30]. Consequently, the current study indicates that the degradation rate of GLP-1 differs across species, and that accurate estimation of GLP-1 secretion in rodents (particularly in mice) requires assays that can cope with this. C-terminal assays may be sensitive to speciesdependent differences in amidation ratios and, as such, may underestimate the secretion of GLP-1 if targeting glycineextended GLP-1 forms, which could be true for rats but not mice [22]. The most versatile assay would not discriminate between amidated and glycine-extended forms. 
In conclusion, GLP-1(9-36) $\mathrm{NH}_{2}$ undergoes further rapid degradation in mice, most likely by NEP 24.11 . This contrasts to its relative stability in some other species, including humans. Therefore, estimation of GLP-1 secretion in mice cannot be made by measuring intact GLP-1(9-36) $\mathrm{NH}_{2}$ levels, but should instead be assessed using C-terminally directed methods capable of measuring the fragment FIAWLVKGR [GLP-1(28-36) $\left.\mathrm{NH}_{2}\right]$, which was identified in plasma in vivo.

Acknowledgements We wish to thank G. Olesen and H. Berg Rasmussen (Department of Psychiatry, Sankt Hans Hospital, Roskilde, Denmark) for assistance with the Luminex instrument.

Data availability The datasets generated during and/or analysed during the current study are available from the corresponding author on reasonable request.

Funding Funding for this research was provided by the NNF Center for Basic Metabolic Research, University of Copenhagen (NNF application number: 13,563; Novo Nordisk Foundation, Denmark), EliteForsk Rejsestipendiat (2016), The Danish Council for Independent Research (DFF - 1333-00206A), the Danish Diabetes Academy (PhD funding), the Augustinus Foundation 14-0962, Aase og Ejnar Danielsens Fond, Mærsk Fonden, Holger Rabitz fond, Læge Johannes Nicolaj Krogsgaard og hustru Else Krogsgaards minde-legat for medicinsk forskning og medicinske studenter ved Københavns Universitet, the European Molecular Biology Organization and the European Foundation for the Study of Diabetes.

Duality of interest The authors declare that there is no duality of interest associated with this manuscript. The authors' (JJH and NJWA) collaboration with Mercodia, regarding measurement of glucagon in humans and in mice, has no relation to the current study. The kits from Mercodia and other companies used in the current study were not complimentary or given at reduced rates, but were obtained at the given market price.

Contribution statement JAW, NJWA, JP and JJH contributed substantially to the concept and design of the study. All authors contributed substantially to the analysis and interpretation of the data. JAW, NJWA and REK drafted the manuscript. SLJ, DH, JP, EPJ, KDG, MW-S, AØ, $\mathrm{CFD}, \mathrm{MM}, \mathrm{HK}, \mathrm{BH}$ and JJH critically revised the manuscript for important intellectual content. All authors have provided approval of the final version to be published. JJH is responsible for the integrity of the work as a whole.

\section{References}

1. Wewer Albrechtsen NJ, Kuhre RE, Torang S, Holst JJ (2016) The intestinal distribution pattern of appetite- and glucose regulatory peptides in mice, rats and pigs. BMC Res Notes 9:60

2. Diakogiannaki E, Gribble FM, Reimann F (2012) Nutrient detection by incretin hormone secreting cells. Physiol Behav 106:387393

3. Tolhurst G, Reimann F, Gribble FM (2009) Nutritional regulation of glucagon-like peptide-1 secretion. J Physiol 587:27-32

4. Hansen L, Deacon CF, Orskov C, Holst JJ (1999) Glucagon-like peptide-1-(7-36)amide is transformed to glucagon-like peptide-1(9-36)amide by dipeptidyl peptidase IV in the capillaries supplying the L cells of the porcine intestine. Endocrinology 140:5356-5363
5. Deacon CF, Pridal L, Klarskov L, Olesen M, Holst JJ (1996) Glucagon-like peptide 1 undergoes differential tissue-specific metabolism in the anesthetized pig. Am J Phys 271:E458-E464

6. Deacon CF, Johnsen AH, Holst JJ (1995) Degradation of glucagonlike peptide-1 by human plasma in vitro yields an N-terminally truncated peptide that is a major endogenous metabolite in vivo. $\mathrm{J}$ Clin Endocrinol Metab 80:952-957

7. Hjøllund KR, Deacon CF, Holst JJ (2011) Dipeptidyl peptidase-4 inhibition increases portal concentrations of intact glucagon-like peptide-1 (GLP-1) to a greater extent than peripheral concentrations in anaesthetised pigs. Diabetologia 54:2206-2208

8. Deacon CF, Ahren B (2011) Physiology of incretins in health and disease. Rev Diabet Stud 8:293-306

9. Kuhre RE, Albrechtsen NJW, Hartmann B, Deacon CF, Holst JJ (2014) Measurement of the incretin hormones: glucagon-like peptide-1 and glucose-dependent insulinotropic peptide. J Diabetes Complicat 29:445-450

10. Hupe-Sodmann K, Goke R, Goke B et al (1997) Endoproteolysis of glucagon-like peptide (GLP)-1 (7-36) amide by ectopeptidases in RINm5F cells. Peptides 18:625-632

11. Hupe-Sodmann K, McGregor GP, Bridenbaugh R et al (1995) Characterisation of the processing by human neutral endopeptidase 24.11 of GLP-1(7-36) amide and comparison of the substrate specificity of the enzyme for other glucagon-like peptides. Regul Pept 58:149-156

12. Plamboeck A, Holst JJ, Carr RD, Deacon CF (2005) Neutral endopeptidase 24.11 and dipeptidyl peptidase IV are both mediators of the degradation of glucagon-like peptide 1 in the anaesthetised pig. Diabetologia 48:1882-1890

13. Hassing HA, Engelstoft MS, Sichlau RM et al (2016) Oral 2-oleyl glyceryl ether improves glucose tolerance in mice through the GPR119 receptor. Biofactors 12:665-673

14. Timper K, Dalmas E, Dror E et al (2016) Glucose-dependent insulinotropic peptide stimulates glucagon-like peptide 1 production by pancreatic islets via interleukin 6 , produced by $\alpha$ cells. Gastroenterology 151:165-179

15. Shirakawa J, Okuyama T, Kyohara M et al (2016) DPP-4 inhibition improves early mortality, $\beta$ cell function, and adipose tissue inflammation in $\mathrm{db} / \mathrm{db}$ mice fed a diet containing sucrose and linoleic acid. Diabetol Metab Syndr 8:16

16. Alamshah A, McGavigan AK, Spreckley E et al (2016) L-arginine promotes gut hormone release and reduces food intake in rodents. Diabetes. Obes Metab 18:508-518

17. Ghanem SS, Heinrich G, Lester SG et al (2016) Increased glucoseinduced secretion of glucagon-like peptide- 1 in mice lacking the carcinoembryonic antigen-related cell adhesion molecule 2 (CEACAM2). J Biol Chem 291:980-988

18. Sayers SR, Reimann F, Gribble FM et al (2016) Proglucagon promoter cre-mediated AMPK deletion in mice increases circulating GLP-1 levels and oral glucose tolerance. PLoS One 11:e149549

19. Seino Y, Ogata H, Maekawa R et al (2015) Fructose induces glucose-dependent insulinotropic polypeptide, glucagon-like peptide- 1 and insulin secretion: role of adenosine triphosphatesensitive $\mathrm{K}^{+}$channels. J Diabetes Investig 6:522-526

20. Wewer Albrechtsen NJ, Hornburg D, Albrechtsen R et al (2016) Oxyntomodulin identified as a marker of type 2 diabetes and gastric bypass surgery by mass-spectrometry based profiling of human plasma. EBioMedicine 7:112-120

21. Wewer Albrechtsen NJ, Bak MJ, Hartmann B et al (2015) Stability of glucagon-like peptide-1 and glucagon in human plasma. Endocr Connect 4:50-57

22. Kuhre RE, Albrechtsen NW, Windelov JA, Svendsen B, Hartmann B, Holst JJ (2014) GLP-1 amidation efficiency along the length of the intestine in mice, rats and pigs and in GLP-1 secreting cell lines. Peptides 55:52-57 
23. Adriaenssens AE, Svendsen B, Lam BY et al (2016) Transcriptomic profiling of pancreatic alpha, beta and delta cell populations identifies delta cells as a principal target for ghrelin in mouse islets. Diabetologia 59:2156-2165

24. Northridge DB, Jardine AG, Alabaster CT et al (1989) Effects of UK 69 578: a novel atriopeptidase inhibitor. Lancet 2:591-593

25. McDowell G, Coutie W, Shaw C, Buchanan KD, Struthers AD, Nicholls DP (1997) The effect of the neutral endopeptidase inhibitor drug, candoxatril, on circulating levels of two of the most potent vasoactive peptides. Br J Clin Pharmacol 43:329-332

26. Orskov C, Jeppesen J, Madsbad S, Holst JJ (1991) Proglucagon products in plasma of noninsulin-dependent diabetics and nondiabetic controls in the fasting state and after oral glucose and intravenous arginine. J Clin Invest 87:415-423

27. Orskov C, Rabenhoj L, Wettergren A, Kofod H, Holst JJ (1994) Tissue and plasma concentrations of amidated and glycineextended glucagon-like peptide I in humans. Diabetes 43:535-539

28. Tyanova S, Temu T, Cox J (2016) The MaxQuant computational platform for mass spectrometry-based shotgun proteomics. Nat Protoc 11:2301-2319

29. Cox J, Neuhauser N, Michalski A, Scheltema RA, Olsen JV, Mann M (2011) Andromeda: a peptide search engine integrated into the MaxQuant environment. J Proteome Res 10:1794-1805

30. Bak MJ, Wewer Albrechtsen NJ, Pedersen J et al (2014) Specificity and sensitivity of commercially available assays for glucagon-like peptide-1 (GLP-1): implications for GLP-1 measurements in clinical studies. Diabetes Obes Metab 16:1155-1164

31. Persson K, Gingerich RL, Nayak S, Wada K, Wada E, Ahrén B (2000) Reduced GLP-1 and insulin responses and glucose intolerance after gastric glucose in GRP receptor-deleted mice. Am J Physiol Endocrinol Metab 279:E956-E962

32. Ahlkvist L, Brown K, Ahrén B (2013) Upregulated insulin secretion in insulin-resistant mice: evidence of increased islet GLP1 receptor levels and GPR119-activated GLP1 secretion. Endocr Connect 2:69-78

33. Marguet D, Baggio L, Kobayashi T et al (2000) Enhanced insulin secretion and improved glucose tolerance in mice lacking CD26. Proc Natl Acad Sci 97:6874-6879

34. Shiota C, Larsson O, Shelton KD et al (2002) Sulfonylurea receptor type 1 knock-out mice have intact feeding-stimulated insulin secretion despite marked impairment in their response to glucose. J Biol Chem 277:37176-37183

35. Petersen N, Reimann F, van Es JH et al (2015) Targeting development of incretin-producing cells increases insulin secretion. J Clin Invest 125:379-385
36. Rydgren T, Börjesson A, Carlsson A, Sandler S (2012) Elevated glucagon-like peptide-1 plasma levels, as a possible adaptive response, in diabetic NOD mice. Biochem Biophys Res Commun 423:583-587

37. Garibay D, McGavigan AK, Lee SA et al (2016) $\beta$-cell glucagonlike peptide- 1 receptor contributes to improved glucose tolerance after vertical sleeve gastrectomy. Endocrinology 157:3405-3409

38. Kieffer TJ, McIntosh CH, Pederson RA (1995) Degradation of glucose-dependent insulinotropic polypeptide and truncated glucagon-like peptide 1 in vitro and in vivo by dipeptidyl peptidase IV. Endocrinology 136:3585-3596

39. Sharma R, McDonald TS, Eng H et al (2013) In vitro metabolism of the glucagon-like peptide-1 (GLP-1)-derived metabolites GLP-1(936)amide and GLP-1(28-36)amide in mouse and human hepatocytes. Drug Metab Dispos 41:2148-2157

40. Eng H, Sharma R, McDonald TS, Landis MS, Stevens BD, Kalgutkar AS (2014) Pharmacokinetics and metabolism studies on the glucagon-like peptide-1 (GLP-1)-derived metabolite GLP1(9-36)amide in male beagle dogs. Xenobiotica 44:842-848

41. Willard JR, Barrow BM, Zraika S (2017) Improved glycaemia in high-fat-fed neprilysin-deficient mice is associated with reduced DPP-4 activity and increased active GLP-1 levels. Diabetologia 60:701-708

42. Graf K, Koehne P, Gräfe M, Zhang M, Auch-Schwelk W, Fleck E (1995) Regulation and differential expression of neutral endopeptidase 24.11 in human endothelial cells. Hypertension 26:230-235

43. Tomas E, Stanojevic V, Habener JF (2010) GLP-1 (9-36) amide metabolite suppression of glucose production in isolated mouse hepatocytes. Horm Metab Res 42:657-662

44. Robinson E, Tate M, Lockhart S et al (2016) Metabolically-inactive glucagon-like peptide-1(9-36)amide confers selective protective actions against post-myocardial infarction remodelling. Cardiovasc Diabetol 15:1-11

45. Ban K, Kim KH, Cho CK et al (2010) Glucagon-like peptide (GLP)-1(9-36)amide-mediated cytoprotection is blocked by exendin(9-39) yet does not require the known GLP-1 receptor. Endocrinology 151:1520-1531

46. Ban K, Noyan-Ashraf MH, Hoefer J, Bolz SS, Drucker DJ, Husain M (2008) Cardioprotective and vasodilatory actions of glucagonlike peptide 1 receptor are mediated through both glucagon-like peptide 1 receptor-dependent and -independent pathways. Circulation 117:e81 